\title{
"Trans-historizar" o espaço público dentro e fora da aca- demia: desafios para a historiografia e para o feminismo?
}

\section{"Trans-historicizing" the public space inside and outside the acad- emy: challenges for historiography and for feminism?}

\author{
Ana Maria Veiga* e Morgani Guzzo**
}

\begin{abstract}
Resumo: Embora ainda lidem quotidianamente com preconceitos e com visões estereotipadas que os reforçam, homossexuais e pessoas trans implodem, por fim, o "muro" de isolamento que os afastava do convívio social, ganhando as ruas, os cinemas, os mercados alternativo e formal de trabalho, chegando às universidades, como estudantes, professoras ou professores e aos cargos públicos, como os legislativos ou as representações de conselhos e associações. O que parecia ser irremediavelmente abjeto agora afasta-se do espaço habitual das margens. Para o debate, traremos alguns casos de pessoas trans como professoras/es e estudantes e da formação de coletivos que agregam sujeitos em situação de margem dentro de universidades. Abordaremos também a entrada na vida pública, na última década, quando passam a ser eleitos ou eleitas para cargos políticos e aparecem como representantes populares, assumindo posições de liderança. Pensando a trajetória entre a abjeção e o protagonismo, buscaremos nos aproximar da transformação ocorrida na autoestima de nãosujeitos que passaram a "acontecer" no mundo e a existir dentro de outra gama de possibilidades. Entendemos o fenômeno trans dos anos 2000 e 2010 como um acontecimento. Como se deram esses movimentos e como ocorre o empoderamento de sujeitos em situação de margem, é o que este artigo pretende discutir.
\end{abstract}

Palavras-chave: Pessoas trans, Espaço público, Academia, Empoderamento 
* É doutora em história e pós-doutoranda no Programa de Pós-Graduação Interdisciplinar em Ciências Humanas da Universidade Federal de Santa Catarina. Tem como áreas de interesse Estudos de Gênero, História visual, imagem e cinema, Raça/Etnia/Classe na história dos feminismos, História da América Latina. É editora de divulgação da Revista Estudos Feministas e coordenadora de programação do Seminário Internacional Fazendo Gênero/Mundos de Mulheres. E-mail: amveiga@yahoo.com.br

** Jornalista, doutoranda no Programa de Pós-Graduação Interdisciplinar em Ciências Humanas da Universidade Federal de Santa Catarina, com bolsa Capes. Mestre em Letras pela Universidade Estadual do Centro Oeste (Unicentro-PR), e graduada em Comunicação Social com habilitação em Jornalismo pela mesma Universidade (2010). Integra o Laboratório de Estudos em Gênero e História (LEGH/UFSC) e faz parte da equipe editorial da Revista Cadernos de Pesquisa Interdisciplinar em Ciências Humanas (PPGICH/UFSC). Desenvolve estudos nas áreas: estudos de gênero, feminismo, movimentos sociais, estudos culturais, comunicação, identidade, memória e representações sociais. E-mail: morganiguzzo@gmail.com

\begin{abstract}
Although still leading daily with prejudices and stereotyped visions that reinforce them, transgender people implode, finally, the "wall" of isolation that has kept them away from social life; they are hitting the streets, the cinemas, the alternative and formal labor market; they are coming to universities, as students, teachers, and also to public service, such as legislative positions or as representative people inside councils and associations. Trans people, that seemed to be irretrievably abject before, now get away from the borderline spaces that they have been historically occupying. This article brings to the debate a few cases of trans teachers and students and it will discuss the formation of student collectives at the university that aggregate people who live in margin situation. It will also discuss their entering in public life, in the last decade, when trans people appear as popular representatives, assuming leadership positions. Thinking of paths between abjection and protagonism, we aim to get closer to the transformation that took place in the self-esteem of not-subjects that started to "happen" in the world, and that came into existence within another range of possibilities. We understand the 2000's and 2010's trans phenomenon as a happening. How these movements, marked by prejudice, have taking place and in which ways the empowerment of these subjects occurs are questions that this article intends to deal with.
\end{abstract}

Keywords: Transgender, Public space, Academy, Empowerment.

\title{
Introduzindo a questão trans
}

No dia 9 de dezembro de 2013, a Universidade da Integração Internacional da Lusofonia Afro-Brasileira (UNILAB), situada no Ceará e na Bahia, dava posse à primeira professora universitária travesti do Brasil. Menos de três anos depois, a mesma professora, Dra. Luma Nogueira de Andrade, 
profere a conferência de abertura do ano letivo na Universidade Federal de Santa Catarina, no Sul do país. O motivo da escolha? A visibilidade alcançada por sujeitos LGBTTTI - sigla que agrega lésbicas, gays, bissexuais, travestis, transexuais, transgêneros e intersexuais - no Brasil na última década.

Da abjeção ao reconhecimento e respeito social, os casos se multiplicam e já podem ser analisados em série. Eles nos instigam a refletir sobre o momento histórico que atravessamos, sobre o que chamamos neste artigo a "trans-historização" de um acontecimento: a emergência da luta de pessoas trans na sociedade brasileira e a consequente ocupação por essas pessoas de outros lugares sociais - lugares de visibilidade e de reconhecimento público.

Podemos entender a questão como um processo de "migração" que ocorre aos poucos, de um não lugar, às margens da sociedade, para uma centralidade em ativismos políticos, debates acadêmicos e nas políticas públicas de inclusão. Este processo, no entanto, deixa evidente os enfrentamentos, as perdas que ocorrem durante o caminho e a certeza de que mais do que lutar por avanços, a militâncias das pessoas T's reflete a necessidade de luta pelo direito à vida e por uma existência socialmente digna.

O presente trabalho se desenvolve a partir da epistemologia feminista, isto é, da concepção da produção de conhecimento que resulta da interação entre teorias e práticas políticas. O pensamento feminista, portanto, está longe de se constituir como um todo unificado. Ao ter em conta as especificidades dos sujeitos sociais em tela, nossa abordagem persegue a linha epistemológica pós e decolonial, que propõe à mudança do enfoque eurocêntrico, androcêntrico e objetivista das teorias do "Norte", isto é, o conhecimento científico produzido nos países da Europa e nos Estados Unidos, para uma teorização a partir do "Sul”, a "periferia" da produção do conhecimento.

A perspectiva decolonial, ou pós-colonial, coloca em foco as experiências e teorizações construídas por sujeitos que durante séculos foram considerados os "Outros", "os periféricos", "os nativos", aqueles que eram lembrados pela ciência como "objetos de pesquisa". Na linha da questão proposta por Gayatri Spivak em seu ensaio "Pode o Subalterno falar?"1, os sujeitos marginalizados, subalternizados, esquecidos ou apagados pela História (como disciplina, com $\mathrm{H}$ maiúsculo) ultrapassam as barreiras de suas marginalidade e alcançam espaços de fala e de escuta. A universidade é um desses espaços possíveis.

Por meio do relato de sujeitos trans, este artigo tem como proposta ser, também, um espaço de "voz" para a trans-historização dessas existências, da luta, da militância e dos embates que essas pessoas vivem para migrar de seres abjetos a sujeitos políticos na sociedade contemporânea.

\section{De abjetos a sujeitos políticos: os caminhos abertos pelo trans-ativismo}

As vidas de pessoas trans são, via de regra, demarcadas pela 
transgressão. A não identificação de seus corpos com sua subjetividade gera efeitos que ultrapassam a perspectiva pessoal, de decisão individual, atingindo social e politicamente os espaços. Ser trans é um ato político de enfrentamento à heteronormatividade e à cis-generidade ${ }^{2}$, regras impostas para as pessoas existirem em sociedade. Assim, a presença de pessoas T's nos espaços foi, durante muito tempo, causa de desconfortos e polêmicas, o que resultou em sua completa exclusão de qualquer espaço que não fosse o das margens: o trabalho em prostituição, o silêncio e, muitas vezes, a depressão e a morte.

Um estudo realizado por Igor Queiroz ${ }^{3}$ evidencia que as notícias sobre travestis, publicadas pelo jornal Diário Catarinense entre os anos de 1980 e 1990, constroem duas posições de sujeito bastante demarcadas para essas pessoas: as perigosas, violentas e criminosas e as das histórias sem continuidade de crimes que as transformam em vítimas. Assim, para Queiroz, travestis são notícia geralmente em casos de violência, cujo discurso jornalístico sensacionalista vincula o termo "travesti" ao perigo, ao crime, a doenças e à prostituição. Assim, a "imoralidade" e a inadequação da existência dessas pessoas as mantêm no lugar da marginalidade, subalternidade e, por fim, numa necessária resistência.

Outra pesquisa desenvolvida por Igor Queiroz ${ }^{4}$ demonstra que as arbitrariedades e violências cometidas na Grande Florianópolis contra as travestis incitaram a emergência da mobilização política das mesmas. Após inúmeros casos de violação de seus direitos civis por policiais e pelo próprio discurso jornalístico, um grupo de pessoas decide criar uma associação para defender os direitos de homossexuais e travestis na região metropolitana da capital catarinense. Por meio de uma carta enviada em 20 de novembro de 1992 ao jornal Diário Catarinense, a Adedh (Associação em Defesa dos Direitos Homossexuais/Região da Grande Florianópolis) é criada com sede provisória junto ao Grupo de Apoio de Prevenção à AIDS (GAPA) da capital. A carta, assinada por Claudio Orlando dos Santos - a Clô, mulher trans então presidenta da associação - após publicada, começa a pautar no principal veículo jornalístico catarinense notícias sobre resistência e reivindicações de pessoas homossexuais, travestis e trans na região de Florianópolis.

As notícias sobre a Adedh, analisadas por Queiroz ${ }^{5}$, apontam que a proposta da associação era atuar em áreas de saúde, jurídica, social e lutar legalmente contra comportamentos lesivos aos direitos humanos de todos os homossexuais. Em junho de 1993, a associação promoveria o $1^{\circ}$ Encontro Regional Sul de Homossexuais, em Florianópolis, com debates e palestras sobre temas como Aids, crimes violentos e preconceitos. Também tinham como proposta normatizar os comportamentos das travestis que trabalhavam nas ruas e intervir junto às forças policiais. A atuação de Clô partia de uma estratégia de negociação tanto com as travestis quanto com os policiais e, também, de um diálogo com organizações brasileiras mais antigas de defesa aos direitos 
de homossexuais, como o Grupo Gay da Bahia $(\mathrm{GGB})^{6}$. A politização da homossexualidade ajudou a agregar novos significados a partir da mobilização das travestis. As vidas, que eram tiradas pelas arbitrariedades policiais ou pelo preconceito, passaram a ganhar importância nas páginas jornalísticas, apesar de os números não diminuírem.

Os dados sobre assassinatos de homossexuais e pessoas T's no Brasil são alarmantes. Práticas discursivas que associam a homossexualidade à doença, ao desvio sexual, à perversão e ao distúrbio comportamental são cotidianas, inclusive nas manifestações públicas de políticos brasileiros (vereadores, deputados estaduais e federais, principalmente, ligados às bancadas religiosas). Embora a Anistia Internacional tenha considerado a homofobia uma violação dos direitos humanos, no Brasil não há nenhuma legislação específica que criminalize esses discursos e práticas violentas contra lésbicas, homossexuais, travestis, transexuais e transgêneros.

De acordo com pesquisa realizada no Grupo Gay da Bahia (GGB), a chance de uma pessoa homossexual ou T ser vítima de assassinato é 80 vezes maior no Brasil do que no Chile. O Brasil é o campeão mundial de crimes motivados pela homo/transfobia. Segundo as agências internacionais, mais da metade dos assassinatos de transexuais em 2014 foram cometidos no país ${ }^{7}$. De acordo com o Relatório “Assassinato de LGBT no Brasil” de 2015, 318 pessoas LGBT foram assassinadas em 2015: um crime de ódio a cada 27 horas. Destes, $52 \%$ gays, $37 \%$ travestis, $16 \%$ lésbicas, $10 \%$ bissexuais, $7 \%$ heterossexuais confundidos com gays e $1 \%$ amantes de travestis. Proporcionalmente, travestis, transexuais e transgênero são as principais vítimas. O risco de uma pessoa $\mathrm{T}$ ser assassinada é 14 vezes maior que um gay. De acordo com o mesmo relatório, que aponta o alto nível de crueldade desses assassinatos, caracterizando crimes motivados por ódio, a impunidade é frequente e estimula novos casos. Somente em um quarto dos homicídios o criminoso é identificado (94 de 318) e menos de $10 \%$ das ocorrências redundou em abertura de processo e punição dos assassinos. O relatório aponta também o alto índice de subnotificação, já que a Polícia não registra o homicídio como motivado por homo/transfobia e, muitas vezes, sequer identifica a vítima como uma pessoa trans ou travesti nos seus relatórios. ${ }^{9}$

A reportagem "Com 600 mortes em seus anos, Brasil é o que mais mata travestis e transexuais", publicada no dia 13 de novembro de 2015, pela Agência Brasi1 ${ }^{10}$, demonstra que a cultura homofóbica do Brasil é a principal responsável pelo elevado índice de assassinatos e outros tipos de violência cometidos no país ${ }^{11}$. De acordo com o Relatório sobre Violência Homofóbica no Brasil, de 2012, o recebimento de denúncias pelo Disque 100 aumentou de 3.084 em 2011 para 4.851 em 2012 (aumento de 1767 casos). Deste número, as violências psicológicas são as mais frequentes, com $83,2 \%$ do total, seguidas de discriminação, com $74,02 \%$ e violências físicas, com $32,68 \%$. De acordo com 
a entrevistada pela reportagem, Symmy Larrat, a primeira travesti a ocupar a função de coordenadora-geral de Promoção dos Direitos LGBT da Secretaria Especial de Direitos Humanos, é incompreensível o modo como as travestis e transexuais são tratadas na sociedade brasileira. Além disso, a dificuldade para obter uma identidade com nome e gênero com o qual se identifica é um grande desafio na legislação brasileira (pessoas $\mathrm{T}$ precisam recorrer à justiça, o que demora às vezes anos, para obter decisão favorável de troca de documentos).

A violência psicológica e a exclusão social de travestis, transexuais e transgêneros são as principais razões para a marginalidade e a insegurança dessas pessoas. A atual presidenta da Associação em Defesa dos Direitos Humanos com Enfoque na Sexualidade (ADEH), de Florianópolis, Lirous K'yo Fonseca Ávila, acredita que a principal dificuldade para as pessoas T's seja o mercado de trabalho. O preconceito e a discriminação impossibilitam que essas pessoas tenham uma existência digna socialmente, razão pela qual muitas entram na prostituição e desenvolvem problemas sérios de depressão. Para Lirous, a preocupação com a saúde deve considerar, também, a saúde mental dessas pessoas.

Eu acredito que o principal é o mercado de trabalho. Tanto é que a minha esperança na ADEH é mudar todinha a realidade que tinha sido posta anteriormente. A instituição tinha como base a prevenção, projetos governamentais e que fossem nessa linha DST/HIV/AIDS. Não que isso não seja importante, mas só que, para eu conseguir fazer um trabalho de saúde, eu preciso pensar na saúde mental, que nunca foi pensada. Então, primeiro, eu quero trabalhar a questão da saúde mental. Por que eu quero chegar nesse ponto? Porque muitas vezes, se você for entrevistar qualquer menina que faz programa, você vai saber que elas sabem nomes de todas as doenças, que elas sabem como não se pega; se ela pega, o que ela vai fazer, é capaz de ela te dar uma aula. Porque a gente, enquanto instituição, sempre fez esse trabalho durante muitos anos. Só que tem muitas que pensam assim: "minha vida é uma bosta, se eu pegar alguma coisa, foda-se". Por quê? Por que não têm autoestima. Então, a necessidade de primeiro fazer um trabalho de saúde mental coletiva, que a pessoa se identifique dentro dos espaços, que ela se sinta proprietária do ir e vir, isso é super importante. Tem gente que bate na Adeh para a gente acompanhar para ir fazer compras, porque elas não têm coragem de entrar nas lojas. Entendeu? [...] Então são pequenas coisas. Isso por exemplo, não passou muito pelo meu cotidiano, porque eu tive o apoio da família, não entrei na prostituição, então isso 
foi uma coisa que me fortaleceu também. [...] E observava a população trans que são profissionais do sexo com outro olhar, não o da experiência, da vivência, e eu comecei a perceber essas coisas, o quanto a realidade que é dada dificulta a elas o acesso do trabalho. ${ }^{12}$

Ao relatar sua experiência ${ }^{13}$, Lirous aponta o quanto foi importante o apoio de sua família durante o seu próprio processo de transição. Para ela, é a base familiar que vai evitar que a pessoa se torne, em algum determinado momento, vulnerável. Porém, quando isso não é possível, grupos e coletivos acabam proporcionando um apoio importante.

Hoje acadêmica de Serviço Social pela Universidade Federal de Santa Catarina (UFSC), Lirous já pensa no projeto de mestrado e nos desafios que estão por vir. Porém, pontua que a sua experiência é diferente da grande maioria dos casos que a Adeh trabalha diariamente. A falta de apoio familiar, isto é, das pessoas que são, geralmente, as mais próximas, é uma das causas de muitas meninas saírem da casa da família e terem que buscar alguma forma de subsistência. Não encontrando, devido ao preconceito das empresas em contratar pessoas trans (mesmo após obterem a retificação do nome), acabam indo para a prostituição. Embora defenda a necessidade de regulamentação das profissionais do sexo, Lirous identifica que há, muitas vezes, uma relação de exploração das meninas trans nas casas de cafetinas. Segundo ela, a carência afetiva das meninas é tão grande, que elas veem na cafetina uma mãe, aquela que acolheu, que cuida. Após o laço ter se estabelecido, é difícil fazer com que percebam a relação de exploração. ${ }^{14}$

Por isso, Lirous crê na importância de serem criados espaços de acolhimento e ofertas de trabalho alternativos à prostituição que, para muitas pessoas trans, é único caminho possível. A presidenta da Adeh tem como proposta a construção do "Projeto Casulo", isto é, uma casa onde as pessoas trans possam morar, trabalhar, estudar, criar laços e usufruir de outras possibilidades de existência ${ }^{15}$. Enquanto se tenta conseguir verba para esta casa, a Adeh, em parceria com o curso de Economia da Universidade Federal de Santa Catarina (UFSC), promove um projeto de economia solidária direcionado às pessoas trans. Por meio da produção de camisetas, chinelos, capinhas de $\mathrm{CD}$, entre outros produtos, seis pessoas trans conseguem outra forma de sustento. Seis vidas que ficarão, por enquanto, fora da prostituição.

A luta por dignidade faz com que muitas pessoas trans alcancem o empoderamento, tanto pessoal quanto dentro do movimento LGBT. Este empoderamento aumenta a visibilidade sobre a especificidade das opressões que as atravessam e os desafios a elas colocados: a retificação do nome e do gênero nos documentos, o acesso aos banheiros, a segurança, entre outros direitos básicos que, negados, impossibilitam a existência de pessoas trans em vários espaços. Lirous argumenta que o caminho para uma transformação social, 
para o fim do preconceito e do medo que atravessa seus corpos, passa pelo acolhimento das famílias, o debate sobre a binaridade de gênero nas escolas, as mudanças no mercado de trabalho, com a criação de cotas para a presença de trans nas empresas ou abatimento no imposto de renda, por exemplo e a melhora no atendimento de saúde para essas pessoas.

A inserção de pessoas trans é um projeto de mudança cultural. Neste aspecto, os movimentos LGBT, as mobilizações feministas, as organizações não-governamentais e demais instituições que, como a Adeh, têm trabalhado para que essas pessoas sejam inseridas dignamente na sociedade, tornam-se indispensáveis na luta por essa transformação. $\mathrm{O}$ acesso às universidades $\mathrm{e}$ ao mercado de trabalho é, portanto, uma grande vitória diante do contexto brasileiros que nos deparamos hoje.

\section{Professoras/es e alunas/os trans: 0 acesso à universidade}

Em agosto de 2015, Patrícia Aguilera Xavier foi a primeira graduanda a completar um curso usando o nome social na Universidade Federal de Santa Catarina. Orgulhosa e emocionada por ter sido escolhida oradora da turma de Arquivologia, sabia que a partir daquele momento ela seria uma das pessoas trans que estão fazendo a diferença na história recente do Brasil. "Eu deixo um legado positivo para os futuros e futuras estudantes. É como um filho que não gerei sozinha, mas que teve minha parcela de contribuição. Acredito que as coisas serão mais fáceis para os próximos". ${ }^{16}$

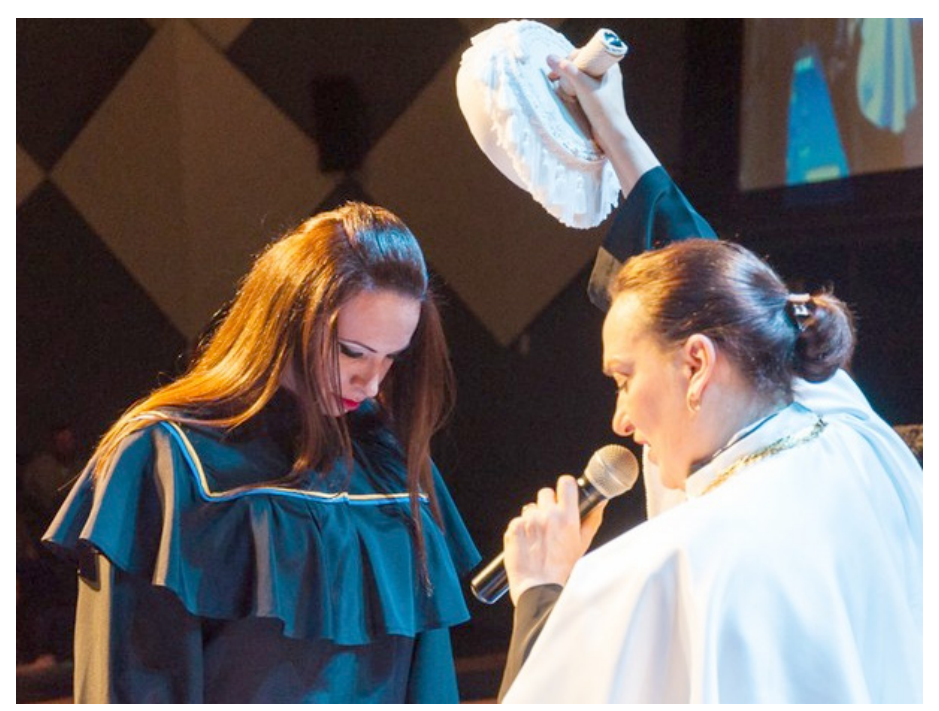

Figura 1: Patrícia Aguilera Xavier recebendo o grau da vice reitora da UFSC, Lúcia Helena Pacheco. 
Fotografia: Henrique Almeida/Agecom/DGC/UFSC. 28.08.2015.

Patrícia representa um grande número de pessoas trans ${ }^{17}$ que estão hoje nos bancos das universidades brasileiras, muitas delas dispostas a seguir a carreira acadêmica, enquanto outras buscam a entrada no mercado de trabalho. A pluralidade de sujeitos se manifesta em seu amplo aspecto, tanto com a inserção de pessoas LGBT, quanto com a entrada de um maior número de pessoas negras e indígenas, que ocupam novos espaços acadêmicos e constroem, além de conhecimento, potência para pensar e agir politicamente. Sabemos que nem sempre foi assim.

O caso vitorioso de Patrícia, que se tornou conhecido por meio de reportagens publicadas em torno de sua formatura ${ }^{18}$ e de um trabalho de conclusão de curso em forma de livro-reportagem ${ }^{19}$, nos dá exemplo de uma trajetória que poderia ter tomado outros rumos. Ela relata que, ainda no ensino fundamental, chegou a ser amarrada dentro de casa, pelo pai, por conta de uma reprovação no colégio. A atitude extrema correspondia ao nível de não-aceitação da família ao sujeito social que começava a se manifestar e a aparecer. A saída de casa e o trabalho em casas noturnas voltada ao público LGBT é um dos caminhos possíveis para inúmeras travestis e transgêneros e foi esta a escolha feita por Patrícia, antes da busca de um emprego voltado especificamente à área de trabalho do curso universitário.

Outra possibilidade que historicamente se afirma para travestis e transexuais é o trabalho na prostituição, como tratamos acima. Tema polêmico em debates acadêmicos, talvez mais do que no ativismo político, a prostituição aparece como horizonte diante da informalidade e da invisibilidade social desses sujeitos. Segundo dados da Articulação Nacional dos Travestis, Transexuais e Transgêneros (ANTRA), cerca de 90\% das travestis brasileiras se prostituem. A exclusão social e a possibilidade de ganhos mais elevados do que os possibilitados com sub-empregos parecem ser os fatores de sedução para a entrada nessa profissão, de acordo com alguns testemunhos. ${ }^{20} \mathrm{O}$ ativismo político e a atuação em grupos buscam afastar o estigma da vitimização desses sujeitos, sendo o reconhecimento profissional uma luta para a garantia de direitos.

A abertura de espaços por meio do estudo para travestis e transgêneros apresenta-se como um acontecimento na história brasileira recente. O nome social é um direito crucial dentro deste processo. Ainda assim, as batalhas por seu reconhecimento e respeito continuam a acontecer dentro de muitas instituições de ensino superior. Patrícia Aguilera relata que chegou a perder um semestre devido à confusão e à humilhação de ter inicialmente seus dois nomes colocados em conflito nas listas de presença, no início do curso ${ }^{21}$. Embora o Conselho Universitário da UFSC tenha aprovado em 2012 o uso do nome social por travestis, transexuais e trangênero nos documentos, registros 
e atos da vida acadêmica ${ }^{22}$, a pouca disposição de alguns professores em acatarem a legislação recente e a desinformação de técnicos administrativos sobre ela também se apresentavam como entraves, em situações diversas. De acordo com reportagem da Agência de Comunicação da UFSC, pela decisão do Conselho Universitário, em agosto de 2015, mês da formatura de Patrícia, "os nomes sociais podem ser utilizados por estudantes, docentes, servidores técnico-administrativos em Educação e participantes de projetos de extensão em todos os níveis de ensino e âmbitos da Universidade". Naquele momento, seis estudantes de graduação e dois de pós-graduação utilizavam nomes sociais na universidade. ${ }^{23}$ No momento da escrita deste artigo, são doze pessoas trans a utilizar este recurso. ${ }^{24}$

Embora o nome social tenha se tornado nos últimos anos um importante instrumento de inclusão social, com seu uso sendo implementado por diversos órgãos públicos e tendo virado lei para os órgãos públicos federais a partir 28 de abril de $2016^{25}$, há atualmente no Brasil um forte movimento de reação a essa conquista no âmbito político partidário. No dia 19 de maio de 2016, deputados dos partidos PSDB, DEM, PSB, PSC, PV, PR, PRB, PROS, PTN e PHS entraram com o pedido de anulação do decreto assinado pela presidenta Dilma Rousseff, que reconhece os direitos mencionados. Apesar das tentativas de retrocesso e reforço da exclusão, com base em argumentos moralistas e/ou religiosos, exemplos bem sucedidos de travestis e pessoas trans começam a ganhar reconhecimento na sociedade brasileira.

Neste ponto, é interessante lembrarmos da provocação e do chamado de Beatriz (hoje Paul) Preciado, que propõe como resposta aos moralismos e à heteronormatividade o estabelecimento de uma "sociedade contrassexual".

\begin{abstract}
A nova sociedade adota o nome de sociedade contrassexual por, pelo menos, duas razões. Uma, e de maneira negativa: a sociedade contrassexual se dedica à desconstrução sistemática da naturalização das práticas sexuais e do sistema de gênero. Duas, e de maneira positiva: a sociedade contrassexual proclama a equivalência (e não a igualdade) de todos os corpos-sujeitos falantes que se comprometem com os termos do contrato contrassexual dedicado à busca de prazer-saber. ${ }^{26}$
\end{abstract}

Ao mesmo tempo em que se busca desnaturalizar e desconstruir antigos padrões sociais, emerge de suas palavras a necessidade de se debater a "equivalência", não mais a "igualdade" proposta por parte do feminismo. A percepção das diferenças e a possibilidade de uma equivalência, ou seja, de valores iguais para todas as pessoas - e aqui falamos das trans - é o objetivo almejado por uma "contradisciplina sexual". 
Luma Nogueira de Andrade é um "exemplo de resistência do grupo social brasileiro mais sujeito à evasão escolar, com índices na casa dos 73\%", segundo a Articulação Nacional dos Travestis, Transexuais e Transgêneros (ANTRA). ${ }^{27}$ Como professora universitária pioneira, Luma tem consciência de ter desafiado a ausência de espaços para pessoas como ela. Além da expressão de sua posse como professora trans, ela foi, anos atrás, a primeira doutora trans do Brasil.

No entanto, não é com tranquilidade que constatamos essa irrupção no cenário acadêmico. Podemos dizer que o convite a Luma Nogueira Andrade para proferir a conferência de abertura do ano letivo na Universidade Federal de Santa Catarina, em 2016, só foi possível devido a uma conjuntura propícia, com o apoio de uma reitora feminista ${ }^{28}$, sensível à temática de gênero e consciente do ato político que significou esse acontecimento. A posse da nova reitoria, a princípio, provoca apreensão de vários grupos a respeito dos direitos conquistados. Assim como se evidencia com amplitude no cenário nacional, o confronto social diante da vulnerabilidade da conquista de direitos de vários grupos historicamente oprimidos é um fator a ter em conta no atual contexto.

Outro exemplo de resistência e vitória no âmbito profissional universitário é o de L.G., professor de uma importante rede federal de ensino. Provavelmente, também, um dos poucos (ou o primeiro) professor trans do Brasil, em nível superior. Em entrevista concedida para esta pesquisa, L.G. argumenta que, para ele, a experiência trans é perpassada por outras questões, como raça, classe e gênero. Assim, as dificuldades se multiplicam. Questões estruturais e culturais, como o preconceito, despertam o medo que, segundo L. G., talvez o maior desafio para as pessoas T's seja enfrentar seus medos, que se manifestam em diversas situações e de variadas formas.

\footnotetext{
Medo de usar o banheiro e algum cara cis perceber que eu tô lá dentro e 'me dar uma lição', isso, porque eu já sou passáve ${ }^{29}$. Mas os meninos que não são sofrem muito com isso. Depois a exigência de que tu seja cada vez mais cis, mais passável... porque todo mundo aceita uma pessoa trans que se passa, sabe, mas enquanto/se você não quer/pode/ consegue, você fica marcado e muitas pessoas te tratam com o pronome errado, muitas vezes em público. Então eu vejo essa exigência de 'ser igual cis' como um problema bem grande, também. A gente nem sempre quer ser esse 'homem' que as pessoas imaginam. ${ }^{30}$
}

A cis-generidade é tida pelas pessoas trans como uma imposição. Se desejam fazer a transição de gênero, tudo bem, desde que se pareçam com o outro gênero. Ou seja, volta-se ao binarismo: ou se é homem, ou se é mulher. 
Essa é um dos principais problemas citados, também, por Lirous, da Adeh. As pessoas não-binárias, isto é, que não se identificam nem com o gênero feminino nem com o gênero masculino, não são aceitas socialmente e sofrem ainda mais para existirem.

Apesar de L.G. poder ser considerado um vencedor, destacando-se socialmente ao alcançar uma carreira almejada por muitos acadêmicos, seu relato demonstra que não existiu facilidade nenhuma em sua trajetória.

Aí vem a questão do emprego. Quando fui prestar a prova não tive direito ao uso do nome social. [...] quando chegou na prova didática tive que me montar de A., fui de mulher. Eu não podia arriscar a chance da minha vida indo de L.G. Foi horrível!! Me troquei no banheiro do posto do lado, fiz minha pouca barba. Passei, mas até hoje me pergunto se, caso eu tivesse ido de L.G., eu teria passado. Junto a isso, afirmo que passei por cotas, e que, se não fossem elas eu também não teria chance de competição com outras pessoas que passaram e que tinham até especialização do exterior. Eu sempre estudei muito e fui muito dedicado, mas nunca fui nem até o Paraguai, porque sou pobre e preto e em nenhum momento da minha vida tive condições de ir pra Europa. Para pagar meu tempo de estudo eu tive que trabalhar e ainda meu pai pegar muito empréstimo em banco. Então, quando você é trans você tem dificuldades, mas elas mudam também de acordo com outros índices. ${ }^{31}$

O relato de L.G. nos remete às opressões apontadas por Kimberlé Crenshaw ${ }^{32}$ sob o guarda-chuva da "interseccionalidade", que são trabalhadas também por outras autoras que trazem novos questionamentos que partem das experiências desses (não)sujeitos. Seus corpos, atravessados pela ruptura e pela transgressão, são marcados por uma multiplicidade de diferenciações que, articulando-se ao gênero, permeiam suas experiências como seres sociais. A vivência a partir do "terceiro mundo" ou da América Latina, como nos lembram a feminista argentina María Luisa Femenías e a indiana Chandra Mohanty, não pode ser lida em referência a um "sujeito monolítico singular"33, mas sim, devem considerar as várias faces da exclusão, explicar como as fraturas do campo social, estratos de subordinação racial/étnica, sexual, etária, religiosa, econômica, entre outras, se potencializam na opressão de gênero e, inversamente, os modos como a subordinação de gênero potencializa as exclusões de raça/etnia, classe, sexualidade, nacionalidade etc. ${ }^{34}$.

Nesta perspectiva, tratamos a interseccionalidade ou a articulação ${ }^{35}$ de várias relações de poder como categorias que se entrecruzam e não se sobrepõem, buscando compreender a experiências dos sujeitos trans como 
localizadas, constituídas de maneira relacional com espaços e outros sujeitos sociais marcados por conflitos e resistências.

Com o exemplo desse professor trans, buscamos nos aproximar da compreensão de uma experiência que é multiplamente marcada.

Minha experiência trans é toda perpassada por outras questões. De raça, de gênero e de classe. Então, são dificuldades que se multiplicam. O desafios são muitos. Desde ir ao médico até usar banheiro público, passando por questões do trabalho. Acho que essas dificuldades são estruturais. Então, quando decido iniciar minha transição tenho em mente que, além de não ter grana e ser preto, ainda vou ter que passar por várias dificuldades de identificação (a parte burocrática). Quero dizer com isso que, a partir daí, nossos direitos começam a ser tolhidos. ${ }^{36}$

L.G. relata que, por não ter plano de saúde, recorre ao Sistema Único de Saúde (SUS), cujos funcionários geralmente não recebem treinamento adequado para tratar das especificidades de pessoas trans. Desde a/o funcionária/o da recepção até as/os médicas/os, o atendimento é um constrangimento após o outro - para não dizer uma violência. Sem respeito ao nome social ou sem o documento retificado, a vergonha perante as pessoas é inevitável quando a subjetividade e as transformações corporais já não coincidem mais com o gênero e o nome dos documentos. "No registro tem um nome feminino, e eu tenho barba", comenta L.G.

Esse tipo de entrave leva a questões mais graves, como o acesso aos hormônios necessários para a transição. L.G. conta que, sem conseguir que as/ os médicas/os lhe passassem a requisição dos hormônios, precisou recorrer ao mercado informal - uma rotina de muitas pessoas em transição e que sempre representa um risco para a saúde. "Para comprar testosterona volta a questão do documento, em que muitas pessoas não querem te vender porque acham que não é você [...] Quando é feita a venda, muitas farmácias também não aplicam e, por isso, tive que aprender a me aplicar sozinho, na coxa". A falta de preparo de profissionais da saúde faz também com que tratem de questões das pessoas trans de maneira leviana, com base em pressuposições sobre a vida da/o paciente. "Já passei por ginecologistas que nem me perguntaram se eu fazia sexo com penetração e marcaram, sem me questionar, essa informação na ficha de saúde de forma negativa", conta L G.

Com esse tipo de tratamento, a vida de pessoas trans torna-se muito mais difícil. De acordo com L.G., só foi possível conseguir requisição para a compra dos hormônios em farmácias quando abriu o centro especializado, no bairro Lagoa da Conceição, em Florianópolis. O Ambulatório de Atenção 
Primária com médicos de família capacitados para o atendimento de pessoas trans, conhecido como "Ambulatório Trans" está em funcionamento desde 2015 e atende somente pessoas trans, todas as segundas-feiras, das $18 \mathrm{~h}$ às $22 \mathrm{~h}$. O serviço é uma parceria da Adeh com alguns médicos de saúde da família que fazem atendimento de forma voluntária, no mesmo local do Centro de Saúde da Lagoa da Conceição. Sobre o atendimento que é realizado no ambulatório, a presidenta da Adeh, Lirous K'yo Fonseca Ávila, pondera que as melhorias na saúde são indispensáveis, já que esta população dificilmente é atendida na unidade básica. "O problema é que toda moeda tem dois lados. O lado ruim do ambulatório é que às vezes você vai em outro lugar e eles falam assim: 'Não, mas teu lugar é lá'". O preconceito é evidente na recusa do atendimento médico.

Situações como as testemunhadas por L.G. nos leva a refletir sobre o quotidiano intenso de pessoas que vivem o preconceito, a falta de respeito e a dificuldade de acesso aos espaços todos os dias.

Só de ser trans, você já é dificultado pelo mundo, quando você é trans, preto, pobre, se mora em periferia, se a família te apoia ou não... tudo isso varia. Mas pra nenhum de nós é fácil. Tudo é mais difícil pra gente. Tudo que todo mundo faz bem, a gente tem que fazer melhor, pra "provar" que somos bons, mesmo. ${ }^{37}$

L.G. aponta a necessidade de, além de muito estudo e esforço, contar com as políticas públicas para conseguir conquistar o espaço que ocupa hoje. Ele conta que só conseguiu concorrer de igual para igual com outras/os candidatas/os no concurso devido à política de cotas, pois não teve condições de, como alguns de seus/suas concorrentes, complementar sua capacitação acadêmica no exterior, ganhando alguns pontos a mais na nota do currículo. "Eu tive que conseguir todos os meus 'pontos' na raça (e, olha que legal esse sentido duplo)", relata.

Mesmo trazendo o peso das situações de opressão que vivem e que parecem se perpetuar na nossa sociedade, as trajetórias de Luma e de L.G. escapam à vitimização, tornando-se exemplos de caminhos possíveis, ainda que seus meandros necessitem ser atravessados com o uso de estratégias diversas, que são de empoderamento e de ativismo. As redes de apoio e de solidariedade são elementos fundamentais para que isso aconteça.

Assim como os esses, outros exemplos de professoras/es trans são encontrados no estudo que resultou no artigo "Professoras trans brasileiras em seu processo de escolarização", de Neil Franco e Graça Cicillini, publicado pela Revista Estudos Feministas $(R E F)^{38}$. Nele, o autor e a autora buscam dar conta das trajetórias de pessoas trans que são professoras da rede pública de ensino fundamental e médio, abordando situações vividas por elas no momento de sua 
formação, como estudantes. Franco e Cicillini situam o foco de sua abordagem:

Ao contextualizarmos as posições de sujeito ocupadas por professoras trans na escola, constatamos que são posições constituídas pelo resultado de processos constantes de resistências e enfrentamentos advindos da educação básica e também da educação superior. Essas professoras representam uma pequena parcela de pessoas trans que conseguiram suportar as imposições heteronormativas em razão da vulnerabilidade social à qual foram expostas desde as fases iniciais da Educação Básica, associadas a processos de exclusão anteriores. ${ }^{39}$

$\mathrm{Na}$ trajetória de cada pessoa trans, constatamos a presença de uma necessária e permanente resistência ao preconceito, que se manifesta nas mais diversas formas no cotidiano desses sujeitos. A luta e o enfrentamento às dificuldades possibilitam, positivamente e gradualmente, que essas pessoas migrem das margens para assumir lugares de visibilidade e respeito.

É nos anos 2010 que vemos surgir mais marcadamente alunas e alunos trans nos bancos das escolas e das universidades, em busca de crescimento pessoal e de carreiras profissionais que antes pareciam inviáveis, devido ao preconceito e ao pré-estabelecimento de papéis e lugares sociais. A heteronormatividade tradicionalmente delimita não apenas regras sociais, mas também lugares, espaços a serem ou não habitados por seres indefinidos para os padrões hegemônicos, pessoas abjetas. Ao lado da construção de seus corpos de acordo com seus desejos, travestis e transexuais têm de dar conta da permanente materialização desses corpos dentro dos centros de educação. Para Preciado,

O sistema sexo/gênero é um sistema de escritura. O corpo é um texto socialmente construído, um arquivo orgânico da história da humanidade como história da produçãoreprodução sexual, na qual certos códigos se naturalizam, outros ficam elípticos e outros são sistematicamente eliminados ou riscados. ${ }^{40}$

Podemos dizer que as pessoas trans, no espaço público, reiteram e reescrevem seus corpos a cada dia, diante das constantes tentativas de apagamento a que estão expostas.

Franco e Cicillini constatam o que este artigo vem também sugerindo, que o ambiente hostil em torno da construção da "identidade" de uma pessoa trans acaba barrando uma ascensão social e o distanciamento da marginalidade, das ruas e da prostituição. ${ }^{41}$ A escola se mostraria como um lugar pouco acolhedor, 
neste sentido. Para os autores, existe uma forma de violência anunciada, que determina lugares de (não)sujeitos e que muitas vezes se consagra em outra forma de violência, esta materializada, com a possibilidade de prejuízo ou violação física sobre a pessoa que se torna exposta. Onze das doze pessoas entrevistadas pelos autores informaram ter sofrido tipos diversos de violências durante o período de formação escolar, como intimidação, assédio, falta de acolhimento, desqualificação. Como contrapartida, relatam seus esforços pessoais para figurarem entre os/as melhores alunos/as de suas turmas. ${ }^{42}$

A heteronormatividade sustenta a exclusão, enquanto esforços quotidianos são realizados no intuito de vencer barreiras constantemente renovadas e socialmente realimentadas. Nos bancos das universidades a situação não é diferente. Franco e Cicillini relatam experiências de algumas de suas entrevistadas. Uma delas afirma que a violência não verbal às vezes pode ser a pior e dá exemplo de colegas que mudavam de lugar na sala para não sentarem ao seu lado, além de lançarem a ela olhares de desprezo e reprovação; outra ouviu de um colega que seu lugar não era na universidade, mas na rua, na prostituição; uma terceira chegou a ser violentada com pauladas e pedradas. ${ }^{43}$

Diante da inexistência ou ineficácia de ações contra a violência de gênero, a transfobia, a homofobia e a lesbofobia dentro das universidades, a formação de coletivos passou a ser vista como uma possibilidade de empoderamento, não apenas para pessoas trans, mas também por parte de outros sujeitos que sofrem preconceito e discriminação, como mulheres e negros/as. Nas palavras do professor L.G., "Ter rede de apoio (manas, grupos de trabalho, de estudo) e política pública, nesse sentido, é a única forma de que a nossa vida ande pra frente" 44 .

\section{A experiência de militância dos coletivos acadêmicos}

Trazemos como exemplos complementares à proposta deste artigo alguns coletivos que se formaram no interior do campus de Florianópolis da Universidade Federal de Santa Catarina. ${ }^{45}$ Entre 2014 e 2015, estudantes fizeram surgir, no âmbito de alguns cursos, mobilizações políticas para buscar representatividade, empoderamento e transformações estruturais, sociais e culturais no espaço universitário. Dentre essas mobilizações, grupos de estudo sobre gênero e feminismo foram criados pelos Centros Acadêmicos de alguns cursos ou por iniciativas de pessoas que sentiram necessidade de discutir questões como a opressão de mulheres e pessoas LGBTTTI (lésbicas, gays, travestis, transexuais, transgênero, intersexuais) nas salas de aula e outros espaços institucionais.

Uma breve análise dos coletivos que surgiram no âmbito das discussões sobre gênero e sexualidade, permite-nos compreender as especificidades, as formas de organização e quais são os sujeitos que se mobilizam nos espaços 
universitários. As motivações e as formas de atuação dos coletivos no âmbito de seus cursos possibilitam reconhecer quais identidades são acionadas pelos membros dos coletivos de maneira estratégica e posicionada, possibilitando, por vezes, uma reflexão sobre as múltiplas opressões que se sobrepõem sobre o mesmo sujeito, como é o caso, também, das mulheres negras.

Trazemos brevemente a experiência do Coletivo Jornalismo Sem Machismo (Curso de Jornalismo/Centro de Comunicação e Expressão), Coletivo DiGA (Diversidade, Gênero e Afirmação/unindo vários cursos do Centro Tecnológico/CTC), Coletivo Migre (Minorias e Gênero em Relações Internacionais/Centro Sócio Econômico) e do Coletivo MUPsi (Mulheres Unidas da Psicologia/Centro de Filosofia e Ciências Humanas). Esses coletivos, autogestionados e de formação horizontal (em oposição às hierarquias verticais, estruturadas de cima para baixo), têm como objetivo comum a proposta de discussão sobre as opressões de gênero e sexualidade nos seus respectivos cursos e a realização de ações de enfrentamento e resistência dos grupos oprimidos.

Quanto aos interesses dos coletivos, três deles estão relacionados aos debates sobre a temática de gênero. De acordo com o relato da acadêmica Clarissa Levy ${ }^{46}$, o coletivo Jornalismo Sem Machismo surgiu da necessidade de discutir a questão de gênero na futura profissão e, também, nas relações com professores e colegas nas salas de aula e outros espaços da universidade. O primeiro espaço de discussão sobre a temática foi proposto pelo Centro Acadêmico do curso de Jornalismo e envolveu somente mulheres. No caso do DiGA (Diversidade, Gênero e Afirmação/CTC), antes de se tornar um coletivo, estudantes se reuniam em um grupo de estudos presencial criado pelo Centro Acadêmico de Engenharia Sanitária Ambiental para discutir gênero. Tanto o grupo de estudos quanto o coletivo que se formou depois sempre foram mistos, compostos principalmente por homens gays e mulheres, independente da orientação sexual. Já o Coletivo Migre (Minorias e Gênero em Relações Internacionais/CSE) começou com a criação, em 2013, de uma página de discussão no Facebook direcionada ao compartilhamento de informações, notícias e propostas de discussão em torno das problemáticas de gênero e sexualidade. Este grupo também era misto e, após um ano de atividade, deparou-se com a necessidade de criar um espaço presencial de discussão entre as acadêmicas e acadêmicos do curso, surgindo assim o coletivo. Diferente dos casos citados, o MUPsi (Mulheres Unidas da Psicologia/CFH) foi mobilizado a partir da reação a um caso específico de opressão de gênero no curso.

A opção por exemplificar os grupos mencionados se dá no sentido da compreensão de que ações e discussões estão sendo realizadas em amplos setores dentro das universidades e que elas revelam a necessidade de união em torno de temas e problemas específicos e se revertem em ações conjuntas para o convívio em uma universidade mais igualitária. 
Quando se pensa em movimentos feministas e LGBTTTI, pressupõese, embora isto não seja uma regra, que haja entendimento comum a respeito das opressões vivenciadas pelos sujeitos que partilham determinada identificação. Sendo assim, tomamos a definição de Stuart Hall para reforçar que a identificação nunca é um dado, uma característica pronta, acabada. Ao contrário, é um processo, uma construção constante, relacionada diretamente com a diferença e com a posição do sujeito no discurso.

É precisamente porque as identidades são construídas dentro e não fora do discurso que nós precisamos compreendêlas como produzidas em locais históricos e institucionais específicos, no interior de formações e práticas discursivas específicas, por estratégias e iniciativas específicas. Além disso, elas emergem no interior do jogo de modalidades específicas de poder e são, assim, mais o produto da marcação da diferença e da exclusão do que o signo de uma unidade idêntica, naturalmente constituída, de uma "identidade" em seu significado tradicional. ${ }^{47}$

Se estivermos de acordo com o autor, entenderemos que o processo de identificação é sempre baseado no contexto e na posicionalidade dos sujeitos nas relações de poder, desempenhando um papel estratégico na mobilização política. Um aspecto interessante a respeito da estrutura dos coletivos aqui mencionados é a criação espontânea de "grupos de reflexão" a partir do compartilhamento de experiências de opressão entre os e as estudantes. Tanto as mulheres membros do Jornalismo Sem Machismo quanto as pessoas do Migre relatam que a primeira atividade presencial dos coletivos foi uma "roda de conversa", onde as pessoas se sentiram confortáveis para falar sobre opressões e violências que sofreram, criando um laço de amizade, de empatia e de ajuda mútua entre as/os presentes. Esse aspecto inicial do coletivo, de criar um "espaço de desabafo", foi relatado por Gabriel Roberto Dauer, do Migre, e por Clarissa Levy, do Jornalismo Sem Machismo, respectivamente.

Curiosamente, com os grupos de reflexão voltamos às estratégias iniciais do feminismo dos anos 1970, quando o primeiro passo dado entre as componentes de um grupo era formar uma roda de conversa para que todas pudessem compartilhar seus problemas e falar sobre a opressão vivida no dia a dia. Ou seja, a opressão social cria mecanismos próprios de defesa e resistência, independentemente de qual grupo seja seu alvo.

A problematização e a denúncia dos estereótipos de gênero reproduzidos na profissão jornalística, por exemplo, evidencia também outro marcador de diferença: o de raça/etnia; afinal, não são raros os casos de coadjuvância de mulheres negras nas empresas de jornalismo. Este aspecto nos remete de volta ao argumento das teóricas pós-coloniais de que as expressões feministas do Sul 
devem ter, sempre, uma preocupação com a opressão de maneira interseccional.

Entendemos que, para além das mulheres, este conceito pode ser apropriado igualmente por pessoas LGBTTTI, tanto em seu processo de conscientização como em estratégias de ação pela obtenção de direitos e equivalências sociais. A sobreposição de exclusões é o que constitui o aspecto interseccional da opressão sobre determinados sujeitos. Talvez por isso, a proposta de se criar espaços de reflexão e empoderamento esteja reunido pessoas com experiências diversas, mas com um objetivo comum: a luta contra formas de opressão que perpassam suas trajetórias.

Stuart Hall argumenta que as identidades são construídas por meio da diferença e não fora dela. Isso implica o reconhecimento de que é por meio da relação com o Outro, da relação com aquilo que não é, que falta, com aquilo que tem sido chamado de seu exterior constitutivo, que o significado "positivo" de qualquer termo - e, assim, sua "identidade - pode ser construído. Mulher (em oposição a homem) e negro (em oposição a branco) são marcas (termos marcados) em contraste com os termos não marcados, dominantes/ hegemônicos. Assim, as identidades proclamadas são construídas no interior do jogo do poder e da exclusão. A afirmação da identidade e a marcação da diferença implicam, sempre, as operações de incluir e excluir. ${ }^{48}$

Apesar de possibilitar processos de identificação e militância, a universidade ainda é um espaço restrito para alguns grupos. Assim, a discussão de gênero dos coletivos deve levar em conta o recorte de raça, classe, sexualidade e posição social, isto é, a quase ausência de jovens de periferia, pobres, mulheres negras, pessoas indígenas e pessoas trans. Para que haja a visibilidade de outros tipos de opressão, uma estratégia pode ser trazer perspectivas novas para dentro do coletivo, que ampliem os debates e alcancem um maior número de estudantes, gerando ações mais diretas. Agregar sujeitos em situação de margem ${ }^{49}$ - incluindo pessoas trans - para que possam transformar a realidade ao seu redor é, também, um desafio aos coletivos na universidade.

Apesar de recentes e ainda de atuação restrita, os coletivos mobilizam ações voltadas ao questionamento, ao enfrentamento e à transformação dos valores que oprimem os diversos grupos que convivem no âmbito universitário. São espaços ainda em construção, que possibilitam o reconhecimento de suas subjetividades, um exercício pleno de aprendizagem com o Outro e, muitas vezes, o primeiro contato de muitos sujeitos com a militância política.

\section{Ação política e ocupação de cargos públicos}

Outro exemplo de trans-ativismo político vem do sertão do Piauí, onde a travesti Kátia Tapety atua, desde os anos 1990, na vida pública de Colônia do Piauí, um município emancipado da primeira capital do estado, a cidade 
de Oeiras. A história de Kátia ganhou bastante repercussão, por ter sido ela a primeira travesti eleita para um cargo público no Brasil e a vereadora mais votada de Colônia por três eleições. Esteve no programa de Jô Soares em 2010, quando foi vista por Karla Holanda, a professora e pesquisadora de cinema que virou cineasta ao dirigir o documentário Kátia, de 2012. ${ }^{50}$ Kátia Tapety virou tema de artigos acadêmicos também. ${ }^{51}$ Os trabalhos em torno de seu protagonismo buscam valorizar o exemplo para outras travestis e transexuais, acenando com um caminho possível de emancipação e de ativismo político, aberto por Kátia e por tantas outras que se empenham em melhorar as condições de vida, de saúde, de reconhecimento dos sujeitos em situação de margem.

No artigo "Kátia Tapety: ora mulher ora travesti? Gênero, sexualidades e identidades em trânsito no Brasil", o antropólogo Fabiano Gontijo inicialmente destaca sua eleição com o nome civil, José Nogueira Tapety Sobrinho, para depois falar da aura de sucesso e reconhecimento em torno de Kátia, membro excluído de uma tradicional família de políticos da região. Gontijo informa que Kátia concluiu os estudos por correspondência, já que seu pai não a deixava estudar, tornando-se auxiliar de enfermagem, parteira e arrancadora de dentes. Virou importante referência em saúde, desenvolvendo também projetos e campanhas de luta contra a disseminação de doenças sexualmente transmissíveis. ${ }^{52}$ Mais adiante em seu texto, Gontijo sugere que, mais do que uma travesti, Kátia é vista como uma "mulher" no lugar onde vive, "(quase) como qualquer outra". O autor argumenta que Kátia teria uma transitoriedade, que aciona de acordo com o contexto em que está inserida. Mulher, para seu trabalho de assistência comunitária na cidade de Colônia do Piauí; travesti, para o mundo exterior, onde participa de encontros e do ativismo em âmbito mais amplo. ${ }^{53}$

Stuart Hall afirma que o significado não está no objeto ou na pessoa, ele não está simplesmente no mundo, sendo determinado por nós. Para este autor, "O significado é construído pelo sistema de representação. Ele é construído e fixado pelo código, que estabelece a correlação entre nosso sistema conceitual e nosso sistema de linguagem." 54

Mais do que pensar em uma dupla identidade, preferimos pensar em diversas identificações (interseccionais) que se sobrepõem e que são acionadas em momentos estratégicos, também na autorrepresentação do sujeito Kátia, que é e pode ser tudo o que quiser. Neste artigo, escolhemos trazê-la como um dos inumeráveis modelos de ocupação do espaço público por sujeitos LGBTTTIs.

De acordo com Preciado, é preciso "sacudir as tecnologias de escritura do sexo e do gênero, assim como suas instituições." ${ }_{55}$ A autora destaca que é no "espaço de paródia e de transformação plástica que aparecem as primeiras práticas contrassexuais como possibilidades de uma deriva radical com relação ao sistema sexo/gênero dominante". É possível inferir que a trans-ocupação de espaços por corpos plasticamente transformados é, também, uma forma de 
expressão e de subversão da norma.

Cada vez mais, pessoas trans ocupam espaços e cargos públicos, identificando-se (ou não) como travestis ou como mulheres. Sua emergência em lugares e cargos pouco esperados, como a presidência de conselhos voltados para os direitos das mulheres, nos mostra, cada vez mais, a busca de uma trajetória de ativismo que as aproxima dos feminismos contemporâneos. Pensar esta relação apresenta-se como um desafio importante, tanto para os feminismos, como para o movimento LGBTTTI.

Kelly Vieira Meira, presidenta do Conselho Municipal dos Direitos da Mulher (CONDIM) da cidade de Florianópolis, é a primeira transgênero líder de órgão em defesa dos direitos das mulheres no Brasil. Graduanda em Ciências Sociais pela UFSC, a ativista também foi reconhecida publicamente ao receber da Câmara dos Vereadores de Florianópolis a medalha Antonieta de Barros, em março de 2016. Sua identificação enquanto mulher pode ser considerada recente (cerca de três anos), mas tempo suficiente para mudanças drásticas em sua vida. Sua transformação envolveu o processo judicial de alteração do nome, condição posta por ela para que decidisse ingressar na universidade; superação da depressão e passagem por instituições como a Adeh, a Rede Nacional Feminista de Saúde e a Casa da Mulher Catarina (primeiro órgão feminista de Santa Catarina). Em entrevista dada ao jornal Diário Catarinense, Kelly vê a militância como parte crucial para seu empoderamento.

Tomei consciência política e dei sentido para aquilo que não tinha sentido. Há possibilidade de mudança se você se coloca no enfrentamento. Se você começa a movimentar as estruturas. Se você se permite a partir de sua vivência desconstruir algumas coisas, pensar junto, elaborar um processo de humanização de um conjunto da sociedade ${ }^{56}$.

Mais do que apenas a ocupação de um espaço público, a trajetória política de Kelly nos fala do empoderamento das mulheres trans e de sua representatividade ao se integrar e defender direitos para todas as mulheres. A postura feminista de Kelly nos leva a pensar sobre a relevância do(s) feminismo(s) como uma frente de resistência, de conquista e de empoderamento, abrangendo todos os tipos de mulheres, mas considerando especificidades.

É por estar no espaço de resistência que pessoas trans sentem a necessidade de se apoiar mutuamente e de buscar seu lugar em espaços compartilhados por segmentos diversos de luta; de, através do pertencimento a um "exterior constitutivo", lutar pela autonomia e pela vida digna. Sua performatividade, tão temida pelas regras de gênero, força as barreiras que as mantêm de fora, age para que saiam do não-lugar, do abjeto, para então tornarem-se sujeitos de fato e de direito. 


\section{Trans-historizando sujeitos e lugares}

Assim como ocorreu nos idos anos 1970, o feminismo mais uma vez se apresenta como caminho para uma diversidade de sujeitos sociais. A força do desejo, dos hormônios e da transformação de sujeitos em permanente mutação, leva-os à procura de um chão firme de união e de reivindicações comuns. Herdam das mulheres a opressão milenar e o estigma de "sexo frágil", fraturado muitas vezes pela constituição material dos corpos que desejam reconstruir. Trazem e são intersectadas pela opressão própria e pela marginalidade como elemento fundador de sua historicidade. No feminismo, (assim como as mulheres negras) as pessoas não-binárias, trans e outras categorias possíveis, buscam demarcar seu ativismo.

Não foi sem polêmica que esta relação se deu. Sônia Maluf problematiza o conflito entre "feministas históricas" e mulheres trans ocorrido no X Encontro Feminista da América Latina e do Caribe, em 2005, que ficou marcado pelos debates em torno da tentativa de integração de um grupo de mulheres trans ao movimento feminista e pelo radicalismo que deles aflorou, na manifestação explícita das feministas que não aceitavam as trans como mulheres. ${ }^{57} \mathrm{Em}$ pouco mais de dez anos, no entanto, essa história foi se transformando.

As pautas mais atuais, muitas delas conduzindo debates importantes no interior dos feminismos contemporâneos, têm seus focos nas demandas de setores específicos e diversos, como as transexuais e transgêneros, as lésbicas, as negras, as mulheres camponesas, marcadas pela afirmação de diferenças no interior do próprio movimento. ${ }^{58}$

Luis Felipe Miguel e Flávia Biroli entendem que os diferentes padrões de dominação e de discriminação se entrelaçam e produzem padrões novos e específicos, mas que é necessário transcender o sem fim das posições particulares para se conceber uma "ação política transformadora", que tem no feminismo seu movimento social, mas também sua potência como teoria política. $^{59}$

Resta-nos refletir sobre quais são as agendas invisíveis, qual é a permeabilidade no interior da academia, por exemplo, em relação a setores que, na história do feminismo, lutaram e ainda lutam por um espaço de reconhecimento, que sujeitos sociais estão invisibilizados ou ausentes, tanto como "objetos" quanto como "sujeitos" da produção acadêmica. ${ }^{60}$

L.G., cuja trajetória foi citada acima, adverte:

A questão de "lugar de fala" pra mim é bem complexa. Sinceramente, acho difícil que vocês entendam o que eu quero falar sem "viver na pele". E, ao mesmo tempo, sei que sem vocês nossa fala não chega em lugar nenhum, porque 
somos, na grande maioria das vezes, caladas e calados. Veja, eu sou o primeiro prof. trans da rede IF (e acho que do Brasil, o que é péssimo). Profa. trans, que eu saiba só tem a Luma na UNILAB. Então, a gente ainda precisa de apoio e, sendo assim, acho que todo mundo tem espaço de fala. A diferença é pra quem fala. Acho ruim uma pessoa cis dizer pra alguém trans o que ela passa, não passa, como deve agir e o que tá acontecendo com a sua cabeça. Mas acho que o governo, por exemplo, não tá preparado pra dialogar com pessoas trans. Nossa luta é essa: queremos falar por nós mesmas! Mas, acho que ficar reivindicando fala e brigando com quem tá tentando ajudar não muda. Temos que brigar pra falar e não com quem tá falando. ${ }^{61}$

Segundo Lirous K’yo, uma das problemáticas das pesquisas é que a pesquisadora vai levar em conta o que as pessoas dizem como uma verdade, então existe uma problematização que deve ser feita, até onde vai a verdade, deve haver um olhar distanciado da pesquisadora diante dos relatos (cita casos em que algumas prostitutas disseram às pesquisadoras que ganhavam milhões, etc). Quanto às pesquisas, Lirous acredita que "Se for possível levar isso pras discussões em sala de aula, se tem esses artigos publicados, a gente consegue. Pode ser que outra pessoa cis não queira utilizar esse material, mas nós, que estamos entrando na academia agora, a gente abraça utiliza para fazer uma difusão deles, e levar isso como uma quebra de preconceito. Eu, quando entrei no serviço social, tinha pouquíssima coisa que falava em travestis e transexuais. Aliás, a gente tem muito pouca coisa e isso é em todas as áreas." ${ }^{\prime 2}$

Para L.G., o critério metodológico, no caso da escrita de pessoas não trans, deve ser redobrado, para se falar de um lugar que não se vive. Tentativas pouco cuidadosas podem ser revertidas em transfobia, sem que este seja o objetivo. Suas palavras nos conduzem a repensar nosso próprio interesse em temáticas que envolvem esses sujeitos. Neste artigo, a sugestão de L.G. está sendo seguida, pois o texto final passou pela revisão de sujeitos abordados, cuja inserção social foi tomada como questão.

Se estamos falando em ativismo também dentro da academia, para além do trânsito entre a universidade e os movimentos sociais, uma das vertentes a ser buscada é a apropriação dessa produção, acrescentando e somando trabalhos, textos, discussões para se fazer o debate, que é feminista e é também negro, indígena, camponês, lésbico, gay e transexual.

Nesse contexto, surgem debates sobre corporalidades, sexualidades, e identidades de gênero, (transfeminismo, transgênero, pós-gênero, pósfeminismo, queer) e outros, trazidos pelas trabalhadoras do sexo, mulheres trans, lésbicas, e bissexuais; setores como a Marcha das Vadias e a Marcha das Mulheres Negras contribuem para as discussões ao impelirem o campo 
feminista para além dos binarismos de gênero e dos essencialismos corporais. Segundo Sonia Alvarez, esses discursos implodem não só a categoria "mulher", mas a própria noção do feminismo, de quem seriam os seus sujeitos privilegiados e sua visão de mundo compartilhada ${ }^{63}$ - elementos centrais na constituição de campos discursivos de ação, incluindo tanto o universo trans quanto os movimentos acima citados. ${ }^{64}$

Para Elias Veras e Joana Maria Pedro, o campo da história ainda é o mais resistente às temáticas queer, críticas à norma "que produz compulsivamente homens e mulheres definidos a partir dos seus sexos biológicos, operação fundante das desigualdades entre os sexos, que exclui homossexuais, lésbicas, travestis e transexuais, não apenas da escrita historiográfica, mas da própria condição de humanos." ${ }^{65}$

Neste sentido, e buscando contribuir com a ampliação do debate, este artigo se aventurou a trans-historizar o acontecimento da irrupção e do empoderamento de pessoas trans na ocupação de espaços diversos na atualidade, como a universidade e os cargos públicos, enquanto esperamos por produções acadêmicas e políticas, como frutos dessa inserção.

\section{NOTAS}

1 SPIVAK, Gayatri C. Pode o subalterno falar? Belo Horizonte: Ed. UFMG, 2010.

2 Referimo-nos a pessoas cujo corpo biológico coincide com sua subjetividade e seu desejo.

3QUEIROZ, Igor. Quando a travesti se torna notícia. In: MOREIRA, R.; KLANOVICZ, L.; CAMARGO, H. W.. (Org.). O gênero e os meios: imprensa, televisão e cinema. 1ed.Londrina: Syntagma Editores, 2014, v. 1, p. 79-91.

4 QUEIROZ, Igor. Entre mortes, perseguições e emergências: a criação da Associação em Defesa dos Direitos Homossexuais da Grande Florianópolis através das páginas jornalísticas. Emblemas (UFG. Catalão), v. 10, p. 167-180, 2013.

5 QUEIROZ, 2013, p. 175.

6 QUEIROZ, 2013; QUEIROZ, 2014.

$7 \mathrm{http}: / /$ transrespect.org/en/en_US/tvt-project/tmm-results/idahot-2015.htm

8 EDITORIA GGB. Bahia: Salvador, janeiro de 2016. Assassinato de LGBT no Brasil: Relatório de 2015. Disponível em: https://homofobiamata.wordpress.com/estatisticas/ relatorios/2015-2/>. Acesso em 28/05/2016.

9 Cf. GOMES, Maurício Pereira. A força de uma palavra: homofobia nas páginas da Folha de São Paulo. Dissertação de Mestrado em História Cultural. Florianópolis: PPGH, UFSC, 2014.

10 CAZARRÉ, Marieta. Com 600 mortes em seis anos, Brasil é o que mais mata travestis e transexuais. Agência Brasil. 13/11/2015. Disponível em: $<\mathrm{http}: / /$ agenciabrasil.ebc.com.br/direitos-humanos/noticia/2015-11/com-600-mortes-em-seisanos-brasil-e-o-que-mais-mata-travestis-e $>$. Acesso em 28/05/2016. 
11 Cf. PRADO, Marco Aurélio M. (et. al.). Travestis e Transexuais no Brasil: ciclos de violência, inteligibilidade institucional e efeitos da invisibilidade. In: VEIGA, Ana Maria; LISBOA, Teresa Kleba; WOLFF, Cristina Scheibe. Gênero e Violências: diálogos interdisciplinares. Florianópolis: Edições do Bosque. No prelo.

12 Lirous K’yo Fonseca Ávila. Entrevista a Morgani Guzzo, em 30 de maio de 2016.

13 Respeitando os princípios metodológicos da história oral, utilizamos neste artigo os testemunhos apresentados tal como foram registrados pelos entrevistadores. Outros relatos foram registrados de forma escrita.

14 Lirous. Entrevista.

15 O Projeto Casulo - Casa de Acolhimento LGBT está no site Vakinha de financiamento coletivo. Disponível em: https:/www.vakinha.com.br/vaquinha/projetocasulo-casa-de-acolhimento-lgbt. Acesso em 31.05.2016.

16 Patrícia Aguilera em entrevista a Fábio Bianchini/AGECOM-UFSC. Disponível em http://noticias.ufsc.br/2015/08/primeira-trans-a-usar-nome-social-na-ufsc-se-forma-emarquivologia/. Acessado em 20.05.2016.

17 Como auto-identificação e posicionamento político, parte dos sujeitos em questão preferem a denominação "travestis" no lugar de "transexuais". Sobre isso, cf. http://tab.uol.com.br/ travestis/\#tematico-8.

$18 \mathrm{Cf}$. http://noticias.ufsc.br/2015/08/primeira-trans-a-usar-nome-social-na-ufsc-se-formaem-arquivologia/.

19 AGUIAR, Beatriz Nedel Mendes. É Patrícia e ponto final. In: Desvairadas: Histórias de gays, lésbicas e pessoas transgêneras na capital de Santa Catarina. Trabalho de Conclusão de Curso (livro-reportagem). Curso de Jornalismo. Florianópolis: Universidade Federal de Santa Catarina, dezembro de 2014, p. 55-60.

20 Cf. http://tab.uol.com.br/travestis/\#tematico-3. Cf. tb. http://www.cartacapital.com.br/blogs/ feminismo-pra-que/o-preconceito-contra-transexuais-no-mercado-de-trabalho-2970.html.

21 Patrícia Aguilera em entrevista a Fábio Bianchini/AGECOM-UFSC. Disponível em http://noticias.ufsc.br/2015/08/primeira-trans-a-usar-nome-social-na-ufsc-se-forma-emarquivologia/. Acessado em 20.05.2016.

22 http://propg.ufsc.br/files/2016/01/Resolu\%C3\%A7\%C3\%A3oNormativa_18C Un2012_NomeSocial.pdf

23 AGECOM/UFSC. Conselho Universitário modifica resolução sobre uso do nome social na UFSC. 13.08.2015. http://noticias.ufsc.br/2015/08/conselho-universitario-modifica-resolucaosobre-uso-do-nome-social-na-ufsc/.

24 Cf. http://cotidiano.sites.ufsc.br/primeira-travesti-a-obter-titulo-de-doutora-no-brasilprofere-aula-inaugural-na-ufsc/.

25 Cf. http://noticias.uol.com.br/politica/ultimas-noticias/2016/05/19/deputados-de-10partidos-tentam-revogar-uso-de-nome-social-no-servico-publico.htm. Cf. tb. http://www. brasil.gov.br/cidadania-e-justica/2016/04/dilma-assina-decreto-que-autoriza-uso-de-nomesocial-no-servico-publico.

26 PRECIADO, Beatriz. Manifesto contrassexual: Práticas subversivas de identidade sexual. Trad. Maria Paula Gurgel Ribeiro. São Paulo: n-1 Edições, 2014, p. 22. 
27 http://cotidiano.sites.ufsc.br/primeira-travesti-a-obter-titulo-de-doutora-no-brasil-profereaula-inaugural-na-ufsc/.

28 Trata-se de Roselane Neckel, que esteve à frente da reitoria da UFSC de 2012 a maio de 2016.

29 Ser "passável” significa parecer realmente um homem, passar-se por homem.

30 L.G. em entrevista às autoras, por correio eletrônico, em 29 de maio de 2016.

31 Idem.

32 CRENSHAW, K. Documento para o encontro de especialistas em aspectos da discriminação racial relativos ao gênero. Estudos Feministas, v.10, n.1, 2002.

33 MOHANTY, Chandra T. Bajo Los Ojos Del Occidente. Academia Feminista Y Discurso Colonial. In: Navaz, Liliana Suárez Y Hernández, Aída (Eds.) Descolonizando El Feminismo. Teorias Y Prácticas Desde Las Márgenes. Madrid: Ed. Cátedra, 2008.

34 FEMENÍAS, María Luisa. Esbozo De Um Feminismo Latinoamericano. In: Revista Estudos Feministas, Florianópolis: Cfh/Cce/Ufsc, Vol.15, No 01, Jan/Abril 2007, P. $11-25$.

35 BRAH, Avtar. Diferença, diversidade, diferenciação, Cadernos Pagu 26, p.329-365, 2006. 36 Idem.

37 Idem.

38 FRANCO, Neil; CICILLINI, Graça A. Professoras trans brasileiras em seu processo de escolarização. Revista Estudos Feministas, v.23, n.2, 2015, p. 325-346.

39 Ibidem, p. 328-329.

40 PRECIADO, Beatriz. Manifesto contrassexual: Práticas subversivas de identidade sexual. Trad. Maria Paula Gurgel Ribeiro. São Paulo: n-1 Edições, 2014, p. 26.

41 FRANCO, Neil; CICILLINI, Graça A. Professoras trans brasileiras em seu processo de escolarização. Revista Estudos Feministas, v.23, n.2, 2015, p. 332.

42 Ibidem, p. 334-335.

43 Ibidem, p. 337-338.

44 L.G. Entrevista. Op. Cit.

45 A abordagem dos coletivos acadêmicos da UFSC fazem parte da pesquisa de Morgani Guzzo, sintetizada no seguinte artigo: GUZZO, Morgani. A efervescência de coletivos feministas na contemporaneidade: identidade, diferença e formas de mobilização. Inédito.

46 As entrevistas com membros de coletivos foram realizadas por Morgani Guzzo, que obteve autorização para o uso dos nomes completos das pessoas entrevistadas.

47 HALL, Stuart. Quem precisa da Identidade? In: Silva, T. T. Identidade e Diferença: a perspectiva dos Estudos Culturais. Petrópolis, RJ: Vozes, 2000, p. 103-133, p. 109.

48 HALL, Stuart. Quem precisa da Identidade? In: Silva, T. T. Identidade e Diferença: a perspectiva dos Estudos Culturais. Petrópolis, RJ: Vozes, 2000. 
49 A conceitualização "sujeitos em situação de margem" é desenvolvida na pesquisa de pós-doutorado de Ana Maria Veiga, intitulada Ativismos feministas nas margens: teorias e mobilização social em torno de eventos interdisciplinares (2005-2015). Em andamento.

50 HOLANDA, Karla. Kátia. Rio de Janeiro, 2012. Produção: Leonardo Mecchi, Alcilene Cavalcante, Karla Holanda, 74 min.

51 Cf. VEIGA, Ana Maria. Kátia - um documentário sobre afetos, política e história. Crítica Cultural, v.10, n.2, Palhoça, SC, jul./dez. 2015, p. 233-242.

52 GONTIJO, Fabiano. Kátia Tapety: ora mulher ora travesti? Gênero, sexualidades e identidades em trânsito no Brasil. Cadernos Pagu, n.43, jul./dez. 2014, Campinas, SP.

53 Idem.

54 HALL, Stuart. The work of representation. In (ed.). Representation: Cultural Representations and Signifying Practices. London: The Open University/Sage Publications, 1997, p. 21. "The meaning is constructed by the system of representation. It is constructed and fixed by the code, which sets up the correlation between our conceptual system and our language system". Tradução Livre.

55 PRECIADO, Beatriz. Manifesto contrassexual: Práticas subversivas de identidade sexual. Trad. Maria Paula Gurgel Ribeiro. São Paulo: n-1 Edições, 2014, p. 27.

56 http://dc.clicrbs.com.br/sc/estilo-de-vida/noticia/2016/03/primeira-transgenero-lider-deorgao-em-defesa-dos-direitos-femininos-no-brasil-e-de-santa-catarina-5113069.html

57 MALUF, Sônia W. Políticas e teorias do sujeito no feminismo contemporâneo. In: SILVA, Cristiane Bereta da; ASSIS, Glaucia de O.; KAMITA, Rosana C. Gênero em movimento: Novos olhares, muitos lugares. Florianópolis: Editora Mulheres, 2007, p. 31-44; e MALUF, Sônia W. Brazilian feminisms: central and peripheral issues. Feminist Review conference proceeding, 2011, p. 36-51.

58 VEIGA, Ana Maria. Gênero e interdisciplinaridade, problemas e questões. No prelo.

59 MIGUEL, Luis Felipe; BIROLI, Flávia. Feminismo e Política: uma introdução. São Paulo: Boitempo, 2014.

60 VEIGA, Ana Maria. Gênero e interdisciplinaridade, problemas e questões. No prelo.

61 L.G. Entrevista. Op. cit.

62 Lirous. Entrevista. Op. cit.

63 ALVAREZ, Sonia E. Para além da sociedade civil: reflexões sobre o campo feminista. In: Cadernos Pagu, Campinas/Sp: Núcleo De Estudos Pagu, N. 43, JaneiroJunho De 2014, p. 13-56.

64 GUZZO, Morgani. A efervescência de coletivos feministas na contemporaneidade: identidade, diferença e formas de mobilização. Inédito.

65 VERAS, Elias Ferreira; PEDRO, Joana Maria. Os silêncios de Clio: escrita da história e (in)visibilidade das homossexualidades no Brasil. Revista Tempo e Argumento, Florianópolis, v. 6, n.13, p. 90 - 109, set./dez. 2014, p. 105. 
Artigo recebido em abril de 2016. Aceito em julho de 2016. 